\title{
Social threat appeals in commercial advertising: The moderating impact of perceived level of self-efficacy and self-esteem on advertising effectiveness
}

\author{
TINE FASEUR, VEROLIEN CAUBERGHE and LISELOT HUDDERS \\ E-Mail: tine.faseur@hubrussel.be; veroline.cauberghe@ugent.be; liselot.hudders@ugent.be
}

\begin{abstract}
This study investigates the impact of the level of fear evoked by an advertisement (for deodorant) framing a threatening social situation. Where the effectiveness of threat appeals has been investigated extensively in health communication, this study focuses on the impact of social threat appeals in a commercial setting. The study investigates the moderating impact of self-esteem on the interaction effect between the level of fear (evoked by a social threat ad) and perceived level of self-efficacy on brand attitude and purchase intention. Results show that for high self-esteem individuals, fear evoked by a social threat is effective, only when perceived self-efficacy is increased (in line with the EPPM). However, for low self-esteem individuals, high versus low perceived self-efficacy does not influence brand attitudes and purchase intentions in case of a social threat appeal, but perceived self-efficacy does increase the effectiveness of appeals in which a positive social situation is shown.
\end{abstract}

Keywords: Social threat, fear appeals, self-esteem, self-efficacy, advertising effectiveness

\section{Introduction}

Threat appeals have been used for many years in advertising to influence individuals' attitudes and behaviors (Bennett, 1996). They are defined as "persuasive messages designed to scare people by describing the terrible things that will happen to them if they do not do what the message recommends" (Witte, 1992, p. 329). It is a message strategy which aims to induce a psychological reaction by evoking feelings of fear among individuals to stimulate certain behavior or reduce unhealthy behavior (e.g., stop smoking, do not drink and drive) (Rotfeld, 1988). However, these threat appeals are mainly studied within the context of health communication, while threat appeals in a commercial marketing context (e.g., for insurances) only received limited academic attention (Hastings, Stead, and Webb, 2004; Tanner, 2006).

In today's cluttered advertising environment, commercial marketers are constantly searching for ways to attract consumers' attention (Lee and Lee, 2007). They may do this by adopting alternative advertising techniques, such as threat appeals. In particular, commercial marketers try to evoke fear by emphasizing the risk or loss of opportunity of not using their product or service (e.g., Sternthal and Craig, 1974; Vincent and Dubinsky, 2004). Similarly to a health communication context, commercial advertisers hope that this fear will incite individuals to alter their behavior, and accordingly, purchase the product (in an attempt to reduce the fear, i.e., danger control). Two types of threat appeals can be distinguished (Laroche, Toffoli, Zhang, and Pons, 2001): physical threat appeals that refer to the physical consequences of not enacting on the promoted behaviors, and social threat appeals that refer to the social disapproval resulting from not using the product (Sternthal and Craig, 1974). Although previous studies mainly focused on the effectiveness of physical threat appeals, recent studies show that social threat appeals may lead to more adaptive coping responses and, accordingly, higher message effectiveness (e.g., Dickinson and Holmes, 2008). 
The Extended Parallel Process Model (EPPM; Witte, 1992) argues that the impact of threat appeals in health communication is moderated by an individual's assessment of his or her capacity to reduce the evoked fear level by implementing the solution proposed in the appeal (i.e., perceived level of self-efficacy). The current study will further investigate whether perceived self-efficacy moderates the effectiveness of social threat appeals in a commercial advertising. In addition, as personality traits may moderate the effectiveness of threat appeals (e.g., Mowen, Harris and Bone, 2004; Ruiter, Abraham and Kok, 2001), the current study will examine the moderating impact of self-esteem on the interaction effect between perceived level of self-efficacy and perceived level of fear evoked by a social threat message on brand attitude and behavioral intention.

\section{Theoretical framework}

\section{Threat appeals}

In the past, various models have tried to explain the underlying mechanism of how threat appeals work (see Witte and Allen, 2000 for an overview). The EPPM (Witte, 1992) is the most recent model that integrates and builds on previous models such as the Protection Motivation Model (Rogers, 1983). According to the EPPM, threat appeals trigger a cognitive process by which individuals appraise the perceived threat as well as the possibility to reduce this threat (efficacy). In a first phase, individuals evaluate the severity of, and their susceptibility to, the threat. Only when they perceive a threat as severe and when they feel vulnerable to this threat, they will experience fear and become motivated to reduce this negative emotion. When this motivation is achieved, people will, in a second phase, evaluate the effectiveness of the recommended behavior (response efficacy), as well as their own ability to perform the recommended behavior to reduce their fear (self-efficacy). Depending on the interaction between these two perceptions (perceived threat and perceived efficacy), the feelings of fear evoked by the threat appeal can result in either a danger or a fear control reaction.

In sum, the EPPM model argues that when the perceived efficacy (i.e., response and/or self-efficacy) is high, people believe they can control the fear evoking threat by engaging in the promoted behavior, leading to positive behavioral intentions (cf. danger control process). However, when the perceived efficacy is low, people will try to reduce the fear in another way, like disregarding the message or searching for counterarguments (cf. fear control process). Although quite some empirical evidence has been found for the EPPM, more empirical research is needed on the potential moderating variables, such as personality traits that might influence the mechanism of the EPPM (e.g., Cauberghe, De Pelsmacker, Janssens, and Dens, 2009; Mowen et al., 2004; Ruiter, Verplanken, De Cremer, and Kok, 2004). Because self-esteem is associated with the quality and dynamics of social relations and feelings related to interpersonal acceptance and rejection (Baldwin, Baccus, and Fitzsimons, 2004), we further investigate whether the impact of high versus low perceived (self-)efficacy in a social fearful condition versus a social positive condition with no threat is different for people with high versus low self-esteem.

\section{Self-esteem}

In general, self-esteem relates to the way people evaluate and appraise their own worth. It consists of all positive and negative thoughts and feelings individuals have about themselves (Campbell, Eisner, and Riggs, 2010). According to sociometer theory, an individual's selfesteem serves as an indicator for one's social inclusion and fluctuates as a function of the 
degree to which one feels valued by others (Leary, Tambor, Terdal, and Downs, 1995). Consequently, self-esteem is especially relevant in the context of social threat appeals, as it reflects an individual's assessment of his or her social achievements, and accordingly his or her vulnerability to social threats (Baldwin et al., 2004). More specifically, previous studies have shown that especially low self-esteem individuals pay more attention to social threat appeals and are more vulnerable to social rejection (Gyurak and Ayduk, 2007; Murray, Griffin, Rose, and Bellavia, 2003).

In the current study, it is our aim to investigate whether the EPPM can explain reactions to social threat appeals for both low and high self-esteem people. In case of a fearful reaction (evoked by a social threat), the EPPM predicts that increasing self-efficacy will lead to more positive behavioral intentions. We believe, however, that for this increased selfefficacy to have an impact, people need to entail a basic level of self-confidence. Previous studies showed that, when people with low self-esteem are confronted with a threat appeal, they are likely to automatically engage in a fear control process. That is because low selfesteem persons have a rather insecure and impoverished sense of belonging and insecure feelings of interpersonal acceptance (Gyurak and Ayduk, 2007; Murray, Bellavia, Rose, and Griffin, 2003). Furthermore, they uphold inadequate coping mechanisms: When being confronted with a fearful situation, low self-esteem individuals are expected to remain passive and be reluctant to buy the promoted product, because this behavior could lower the psychological distance with the fear-evoking situation (i.e., being confronted with the product could make the threat salient again). As a consequence, they will not engage in controlling the danger of the social threat (fear control), even not when self-efficacy is salient (Leventhal, 1971). For low self-esteem individuals, no impact is therefore expected from perceived selfefficacy on threat appeal effectiveness. High self-esteem persons, on the contrary, are feeling more self-confident and are therefore more likely to engage in a danger control process leading to message acceptance, especially when self-efficacy is made salient. They may appraise the message recommendations as being effective and feasible (Leventhal, 1971; Witte, 1992).

This leads to the following hypothesis:

H1: For high self-esteem individuals, a feeling of fear evoked by a social threat will be more effective (more positive attitude toward the brand and higher purchase intention) when self-efficacy is perceived high versus low.

As discussed above, one of the assumptions of the EPPM is that increasing perceived efficacy is only necessary to achieve behavioral change in case of high fear evoked by a threat appeal. For low self-esteem individuals, however, we expect that a high self-efficacy message in the ad may have a positive impact on advertising effectiveness for ads depicting a positive social situation with no threat. Low self-esteem individuals are convinced that others evaluate them negatively and they often experience social rejection (Denissen, Penke, Schmitt, and Van Aken, 2008). Accordingly, when a low self-esteem individual is faced with an ad depicting a rewarding (no fearful) social situation, this individual will experience a large discrepancy between the situation in the ad and his/her own situation. This process is called social comparison - that is, the evaluation of one's attributes by comparing them to the attributes of others (Bower and Landreth, 2001). This process of social comparison has been investigated in the context of idealized advertisements. In particular, research (e.g., Richins, 1991) found that individuals confronted with a highly attractive endorser (a positive appeal) perceived a large self-discrepancy due to social comparison, leading to a lower perceived self-image (Grabe, Ward, and Hyde, 2008). This mechanism can lower the ad effectiveness because the people do not feel able to obtain (cf. low perceived efficacy) the same beauty as the endorser 
by using the promoted product. As with the comparison with an ideal model, we expect the positive social situation with no threat to generate a perceived discrepancy for low self-esteem individuals. This perceived discrepancy will give low self-esteem individuals a confirmation of their low self-worth and even confirm their low sense of belonging (Richins, 1991). Therefore, these individuals may belief that this 'ideal' (positive) social situation is not attainable for them, due to the low perceived ability to achieve that situation. For these individuals, it may be needed to increase the perceived efficacy in idealized advertisements to enhance advertising effectiveness:

H2: For low self-esteem individuals, an ad depicting a positive social situation evoking no fear will be more effective (more positive brand attitude and higher purchase intention) when perceived self-efficacy is high versus low.

Following the EPPM, for high self-esteem individuals, perceived self-efficacy has no significant impact on advertising effectiveness (brand attitude and purchase intention) when an ad depicting a positive social situation evoking no fear.

\section{Method}

\section{Design and stimuli}

To test whether self-esteem moderates the interaction effect between feelings of fear evoked by a social threat appeal and perceived self-efficacy on advertising effectiveness (i.e., brand attitude and purchase intention), a 2 by 2 by 2 between-subjects design was set up. To stimulate some variation in the perceptions of self-efficacy and evoked fear, the level of threat (social threat vs. positive social situation evoking no fear) and the level of efficacy (no versus high explicit self-efficacy) were manipulated in the advertisements. The degree of self-esteem was measured.

Four advertisements were created for a fictitious brand of deodorant (Alveda, see Appendix 1). The four ads contained an identical slogan - Alveda deodorant effective care the whole day through -, an identical picture of the product in the right corner of the ad, and a large picture in the center of the advertisement that varied according to the threatening condition. In the high threat, negative social condition the large picture depicts a situation where a man is standing in the train with bad smelling armpits. A woman, who is standing close to him, is turning her head away due to the smell. In the no-threat, positive social condition the picture shows a man who is embracing two women and they are all smiling. In the conditions where self-efficacy was not made explicit, only the product name and the slogan appeared. In the high self-efficacy conditions, an additional text - you can do something about it - appeared next to the slogan, and also the product website was mentioned in the ad.

\section{Participants, procedure and measures}

Data were collected online from 243 respondents, $61 \%$ women, with a mean age of 22.6 years old $(S D=4.22)$. A convenience sample was recruited by sending e-mails to a panel of a large European University including respondents between 16 and 46 years old. Using the snowball procedure, participants were free to invite their friends to participate in the study.

Participants were randomly assigned to one of the four ads. After a short introduction, participants were asked to watch the print ad (no other instructions, no time constraint). After they viewed the print ad they had to complete the dependent variables. First, attitude toward 
the brand is measured by a three item 7-point semantic differential scale, anchored by the adjectives "bad-good", "negative-positive", and "unfavorable-favorable" $(\alpha=.80)$ (Bruner, Hensel, and James, 2005). Purchase intention is measured by the three-item scale of Putrevu and Lord $(1994, \alpha=.91)$. The six-item scale of Witte (1992) is used to measure the level of fear the ads evoke. In particular, respondents were asked to indicate to what extent they experienced fear (the ad evoked a frightening feeling) on a 7-point Likert-type scale. As the perceived level of fear is more relevant than the manipulations themselves, these scores were used as the first independent variables in the analyses. A median split was used to create two groups (no fear vs. fear). Next, perceived self-efficacy measured the extent to which respondents thought the product would be effective for them to solve the problem (social threat). The scale consists of three items measured with a seven-point Likert-type scale based on the perceived self-efficacy scale of Witte (1992). We used this measure of perceived selfefficacy as independent variable for further analyses. By using a median split, we created two groups (low and high perceived self-efficacy). Finally, self-esteem was measured by the tenitem scale of Rosenberg $(1989, \alpha=.71)$. A median split was conducted on the average of the ten self-esteem items in order to create a new dummy variable with high and low self-esteem individuals. Self-esteem was measured at the end of the questionnaire, and could therefore be influenced by the manipulated variables. However, an ANOVA with the independent variables perceived level of fear and perceived self-efficacy showed no main effects (perceived level of fear: $F(1,231)=.01, p=.94$; perceived self-efficacy: $F(1,231)<.001, p=$ $.99)$ nor an interaction effect of the conditions on self-esteem $(F(1,231)=.40, p=.53)$.

\section{Results}

A MANOVA analysis is conducted with perceived level of fear, perceived level of selfefficacy and self-esteem as the independent variables and attitude toward the brand and purchase intention as dependent variables to test the hypotheses. A significant three-way interaction was found for both brand attitude $(F(1,231)=11.3, p=.001)$ and purchase intentions $(F(1,231)=6.8, p=.01)$. For individuals with a high degree of self-esteem, separate independent sample t-tests revealed that ads that evoked fear are more effective under high perceived self-efficacy than under low perceived self-efficacy (brand attitude: $t(47)=4.31, p<.001$; and purchase intention: $t(47)=2.39, p=.02$ ). H1 is supported (see Figure 1). When no fear was experienced, the message was equally effective under high and low perceived self-efficacy (brand attitude: $t(70)=.76, p=.45$; and purchase intention: $t(69)$ $=.13, p=.90)$.

\section{- INSERT FIGURE 1 ABOUT HERE -}

Figure 2 shows that for individuals with a low degree of self-esteem, ads that evoke fear were equally effective under high and low perceived efficacy (brand attitude: $t(63)=1.35, p=.18$; and purchase intention: $t(63)=.48, p=.63$ ). These results confirm the second hypothesis (see Figure 2). Ads that portray a social situation but evoke no fear were, however, more effective when perceived self-efficacy was high than when perceived self-efficacy was low (brand attitude: $t(52)=2.92, p<.01$, and purchase intention: $t(53)=2.12, p=.04$ ). These results confirm the second hypothesis.

\section{- INSERT FIGURE 2 ABOUT HERE -}

Since self-esteem may differ according to gender (Kling, Hyde, Showers, and Buswell, 1999), and the ad stimuli used in this study only portrayed a man central in the social threatening 
situation, we checked for potential confounding effects of gender. The results of the MANOVA (including perceived fear, perceived self-efficacy, self-esteem and gender as independent variables) showed no significant main or interaction effects on both brand attitude and purchase intentions.

\section{Discussion}

This study investigated the differential impact of perceived fear and perceived self-efficacy evoked by a commercial social threat message on brand attitude and purchase intention for low and high self-esteem individuals. The results show that, in line with the EPPM, a social threat appeal is more effective for high self-esteem people when perceived self-efficacy is high. This does not hold, however, for low self-esteem individuals. For them an increased self-efficacy has no impact on the effectiveness of the social fear evoking message. The results of this study are in line with previous studies showing that fear-evoking advertisements are rather ineffective for people with low self-esteem. These people have inadequate coping mechanisms, restraining them from enacting on the promoted behavior to reduce fear, even when perceived efficacy is salient (Leventhal, 1971).

Next, the results show that when low self-esteem individuals are confronted with ads portraying a positive social situation evoking no fear, an increase in the perceived selfefficacy does lead to higher advertising effectiveness. Whereas for high self-esteem individuals this increased perceived self-efficacy has no impact. These results are in line with previous studies that show that idealized advertisements are detrimental for low self-esteem individuals (e.g., Grabe et al., 2008).

To conclude, this study showed that the EPPM is not applicable for all people, but that some basic trust in oneself is needed for social fear appeals to be effective. From a practical point of view, the results of this study are very relevant for marketers and advertisers. Before deciding to use threat appeals, marketers should try to get an idea of the self-esteem of their target group. For example, Booth (1990) found that the degree of self-esteem of female adolescents is lower than the self-esteem of their male counterparts. If the self-esteem of your target group is rather low, it is best to use no messages that might evoke some feeling of fear. The results of this study even go a step further since for low self-esteem individuals it seems even necessary to boost their perceived self-efficacy for ads depicting positive social events, to increase the ad's effectiveness.

A restriction of this research, however, is that the levels of perceived fear in the highthreat condition were rather low $(M=2.95)$. Possibly, more pronounced effects, or even reversed effects might be found when ads are created that evoke higher levels of fear. Future research could also try to capture the level of 'social' fear instead of using the general measurement instrument. In addition, using different pictures across the conditions might have induced a confounding effect. Future research should also try to control the exposure time to the ad and embed the ad in a series of ads.

Further research on this topic should look at the underlying mechanism of the moderating effect of self-esteem on the effectiveness of social threat messages. The perceived discrepancy between the self-perception and the social situation should be looked at in depth. In addition, it would also be interesting to examine if these results can be replicated for physical threat messages. Are low self-esteem individuals equally affected by these physical threat appeals, although they do not relate to the mechanism of social comparison?

\section{Bionotes}

Tine Faseur is assistant professor in Marketing at the Hogeschool Universiteit Brussel. 
Verolien Cauberghe is assistant professor in Communication Management at Ghent University.

Liselot Hudders is an assistant professor at the marketing department and a postdoctoral researcher at the department of communication sciences at Ghent University.

\section{References}

Baldwin, M. W., Baccus, J. R. \& Fitzsimons, G. M. (2004). Self-esteem and the dual processing of interpersonal contingencies. Self \& identity, 3(2), 81-93.

Bennett, R. (1996). Effects of horrific fear appeals on public attitudes towards AIDS. International Journal of Advertising, 15(3), 183-202.

Booth, N. D. (1990). The relationship between height and self-esteem and the mediating effect of self-consciousness. Journal of social psychology, 130(5), 609-617.

Bower, A. B., \& Landreth, S. (2001). Is beauty best? Highly versus normally attractive models in advertising. Journal of Advertising, 30(1), 1-12.

Bruner, G. C., Hensel, P. J., \& James, K. E. (2005). Marketing scales handbook: A compilation of multi-item for consumer behavior and advertising (Vol. IV). Chicago, IL: Thomson.

Campbell, R. L., Eisner, S., \& Riggs, N. (2010). Sources of self-esteem: From theory to measurement and back again. New Ideas in Psychology, 28(3), 338-349.

Cauberghe, V., De Pelsmacker, P., Janssens, W., \& Dens, N. (2009). Fear, threat and efficacy in threat appeals: Message involvement as a key mediator to message acceptance. Accident Analysis and Prevention, 41(2), 276-285.

Denissen, J. J. A., Penke, L., Schmitt, D. P., \& Van Aken, M. A. G. (2008). Self-esteem and reactions to social interactions: Evidence for sociometer mechanisms across days, people, and nations. Journal of Personality and Social Psychology, 95(1), 181-196.

Dickinson, S., \& Holmes, M. (2008). Understanding the emotional and coping responses of adolescent individuals exposed to threat appeals. International Journal of Advertising, 27(2), 251-278.

Grabe, S. L., Ward, M., \& Hyde, J. S. (2008). The role of the media in body image concerns among women: A meta-analysis of experimental and correlational studies. Psychological Bulletin, 134(3), 460-476.

Gyurak, A. \& Ayduk, O. (2007). Defensive physiological reactions to rejection: The effect of self-esteem and attentional control. Psychological Science, 10(1), 886-892.

Hastings, G., Stead, M., \& Webb, J. (2004). Fear appeals in social marketing: Strategic and ethical reasons for concern. Psychology \& Marketing, 21(11), 961-986.

Kling, K. C., Hyde, J. H., Showers, C. J., Buswell, B. N. (1999). Gender differences in selfesteem: A meta-analysis. Psychological Bulletin, 125, 470-500.

Laroche, M., Toffoli, R., Zhang, Q., \& Pons, F. (2001). A cross-cultural study of the persuasive effect of fear appeal messages in cigarette advertising: China and Canada. International Journal of Advertising, 20(3), 297-317.

Leary, M. R., Tambor, E. S., Terdal, S. K., \& Downs, D. L. (1995). Self-esteem as an interpersonal monitor: The sociometer hypothesis. Journal of Personality and Social Psychology, 68(3), 518-530.

Lee, B. K., \& Lee, W. N. (2007). Decreasing advertising interference: The impact of comparable differences on consumer memory in competitive advertising environments. Psychology and Marketing, 24(11), 919-945. 
Leventhal, H. (1971). Fear appeals and persuasion: The differentiation of a motivational construct. American Journal of Public Health, 61(6), 1205-1224.

Mowen, J. C., Harris, E. G. \& Bone, S. A. (2004). Personality traits and fear response to print advertisements: Theory and empirical study. Psychology and Marketing, 21(11), 927-943.

Murray, S. L., Bellavia, G., Rose, P., \& Griffin, D. (2003). Once hurt, twice hurtful: How perceived regard regulates daily marital interaction. Journal of Personality and Social Psychology, 84, 126-147.

Murray, S. L., Griffin, D. W., Rose, P., \& Bellavia, G. (2003). Calibrating the sociometer: The relational contingencies of self-esteem. Journal of Personality and Social Psychology, 85, 63-84.

Putrevu, S., \& Lord, R. K. (1994). Comparative and noncomparative advertising: Attitude effects under affective and cognitive involvement condition. Journal of Advertising Research, 23(2), 77-90.

Richins, M. L. (1991). Social comparison and the idealized images of advertising. Journal of Consumer Research, 18(1), 71-83.

Rogers, R. W. (1983). Cognitive and physiological processes in fear appeals and attitude change: A revised theory of protection motivation. In J. Cacioppo \& R. Petty (Eds.), Social psychophysiology (pp. 153-176). New York: Guilford.

Rosenberg, M. (1989). Society and the adolescent self-image. Princeton, NY: Princeton University Press.

Rotfeld, H. J. (1988). Fear appeals and persuasion: Assumptions and errors in advertising research. Current Issues \& Research in Advertising, 11(1), 21-40.

Ruiter, R. A. C., Abraham, C., \& Kok, G. (2001). Scary warnings and rational precautions: A review of the psychology of fear appeals. Psychology \& Health, 16(6), 613-630.

Ruiter, R. A. C., Verplanken, B., De Cremer, D., \& Kok, G. (2004). Danger and fear control in response to fear appeals: The role of need for cognition. Basic and Applied Social Psychology, 26(1), 13-24.

Sternthal, B., \& Craig, C. S. (1974). Fear appeals: Revisited and revised. Journal of Consumer Research, 1, 22-34.

Tanner, J. F. Jr. (2006). Read this or die: A cognitive approach to an appeal to emotions. International Journal of Advertising, 25(3), 414-416.

Vincent, A., \& Dubinsky, A. J. (2004). Impact of fear in a cross-cultural context. Marketing Management Journal, 15(1), 17-32.

Witte, K. (1992). Putting the fear back into fear appeals: The extended parallel processing model. Communication Monographs, 59(4), 329-349.

Witte, K., \& Allen, M. (2000). A meta-analysis of fear appeals: Implications for effective public health campaigns. Health Education and Behavior, 27(5), 591-615. 